\title{
EDITORIAL
}

\section{O CONTEXTO POLÍTICO E A EDUCAÇÃO NACIONAL}

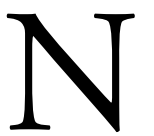

o momento em que este número de Educação e Sociedade chega ao conhecimento de seus leitores, encontra-se em curso um processo de gravíssima ruptura democrática no país, contra o qual se insurgem diversas entidades do campo educacional que vêm se opondo ao impeachment da presidenta Dilma por ele representar um risco sem precedentes aos direitos sociais, educacionais e de cidadania.

Trata-se de barrar a ruptura institucional em andamento e de repor as condiçóes necessárias ao desenvolvimento de políticas públicas educacionais que enfrentem as desigualdades e universalizem o acesso com qualidade social. Se já eram limitadas e contraditórias as políticas educacionais adotadas nos governos da presidenta Dilma, agora, as primeiras medidas anunciadas pelo interino Michel Temer objetivam desconstruir todo o empreendimento político-institucional que, ancorado na Constituição Federal de 1988, permitiu-nos avançar em termos de igualdade e de reconhecimento, ainda que lentamente.

Michel Temer, com seu ministério constituído apenas por homens brancos e ricos, vem tomando medidas que comprometem as conquistas civilizatórias presentes na Constituição de 1988, e tudo isso com uma velocidade que só a ruptura democrática possibilita. Com o argumento da necessidade de equilibrar as contas federais, Temer se apressou em fazer uma reforma administrativa, que extinguiu pastas e fundiu áreas do governo. Fagnani (2016) alertou que "como uma espécie de símbolo (o presidente), colocou a Previdência dentro do Ministério da Fazenda", explicitando "uma face da luta de classes no país". Segundo o autor, as elites financeiras jamais aceitaram que o movimento social dos anos 1970 e 1980 introduzisse na Constituição os direitos sociais cujo atendimento exige $10 \%$ do Produto Interno Bruto (PIB) (FAGNANI, 2016). Trata-se de uma disputa por recursos públicos, de um movimento do capital rumo à apropriação da relativamente pequena margem de recursos estatais protegidos de sua exploração e acumulação.

Nesse contexto, o governo golpista também extinguiu o Ministério da Cultura, fundindo-o ao Ministério da Educação, só voltando atrás, pouco depois, pressionado pela resistência dos movimentos populares de cultura, de artistas e de intelectuais. O Ministério de Ciência e Tecnologia foi "acoplado" ao Ministério de Comunicaçóes, reduzindo um e outro e, ao mesmo tempo, privando a sociedade da responsabilidade do Estado com a pesquisa e projetos nacionais de

DOI: 10.1590/ES0101-73302016v37n135ED 
inovação, indispensáveis para o desenvolvimento da Naçáo. Com isso, se alinham as medidas tomadas pela Coordenação de Aperfeiçoamento de Pessoal de Nível Superior (CAPES) em relação aos cursos de pós-graduação que visavam reduzir os estudos da área das Ciências Humanas, deixando, assim, exposta a concepção de ciência e de mundo desse governo provisório.

Da mesma maneira, extinguiu o Ministério da Igualdade Social, dos Direitos das Mulheres e da Juventude. submetendo o Ministério de Direitos Humanos ao Ministério da Justiça, não por coincidência, entregue à direção do ex-secretário de Segurança Pública do Estado de São Paulo. Este, um conhecido repressor dos movimentos sociais, viajou para tomar posse poucas horas após comandar violentas e abusivas reintegrações de escolas públicas ocupadas por estudantes em luta pelo direito à educação e contra a assim chamada máfia da merenda escolar.

No desmonte anunciado das políticas sociais voltadas aos setores populares, antecipa-se a drástica redução de recursos voltados ao Sistema Único de Saúde (SUS) e à Educação, e a ampliação das desvinculaçóes de receitas para 30\%, passando a alcançar estados, municípios e o Distrito Federal, com graves consequências para saúde e a escolarizaçáo da populaçáo brasileira, excluída do direito democrático de acesso à educação, e prováveis retrocessos para a valorização dos profissionais, em processo de construção. Mais graves são as medidas contidas na Proposta de Emenda à Constituição (PEC) apresentada por Temer com o propósito de reduzir os gastos sociais durante os próximos 20 anos. A limitação de gastos impedirá o cumprimento das metas estabelecidas no Plano Nacional de Educaçáo (PNE), entre elas e, sobretudo, a efetivação da educaçáo obrigatória para todos os jovens entre 4 e 17 anos, o estabelecimento do CAQ/CAQI (Custo aluno qualidade/Custo aluno qualidade inicial) e a valorizaçáo do magistério da educação básica como política obrigatória em todo o território nacional. Caso aprovada e implementada essa PEC, veremos retroceder o acesso às escolas e universidades públicas, como correspondente incrementando de sua privatização.

Uma das primeiras medidas do Ministério da Educação do governo Temer foi exonerar 31 assessores técnicos, 23 deles ligados à Secretaria de Educação Continuada, Alfabetização, Diversidade e Inclusão (Secadi) e mais oito da Secretaria Executiva da pasta, o que afeta, de imediato, as atividades do Fórum Nacional da Educação (FNE) e, como consequência, também os processos de construção da participação social nas políticas educacionais e de monitoramento participativo da implementação do Plano Nacional de Educação (FARIA, 2016). O site do FNE, do Portal do Ministério da Educação (MEC), importante espaço da rede participativa, está sem manutenção, porque o contrato do jornalista venceu e os novos procedimentos estáo suspensos.

Diante disso tudo, são muito preocupantes as perspectivas para o futuro da Educação do País. Temores vão se confirmando em sucessivos sinais emitidos pelo governo interino como, por exemplo, o ocorrido no último dia 31 de maio, na Audiência Pública sobre a Base Nacional Comum Curricular (BNCC), que dava des- 
taque à posição de movimento conservador, em organizaçáo desde 2004, promovido pela Comissão de Educação da Câmara Federal sob a coordenação dos deputados Maria Auxiliadora (Dorinha) Rezende e Rogério Marinho. Foram excluídas importantes entidades de Educação, como a Associação Nacional de Pós-Graduação e Pesquisa em Educação (ANPED), a Associação Nacional pela Formação dos Profissionais da. Educação (ANFOPE) e o Centro de Estudos Educação e Sociedade (CEDES), entre outras, historicamente representativas e articuladoras das discussóes e dos posicionamentos dos educadores da educação básica.

Observou-se, nas manifestaçóes por parte dos participantes desse evento, o objetivo de impor as BNCC como uma das principais políticas de Estado. Também ganhou espaço no núcleo dirigente do MEC, fortalecendo o Movimento pela Base Nacional Comum, que propóe definir o conteúdo da educação básica brasileira em uma base comum, série a série, na forma de padrōes para todas as áreas definidas pelo MEC, com o objetivo de promover o processo de avaliaçáo e controle em larga escala.

Como destacado por Freitas (2016), o que está em jogo nesse momento é a natureza da base nacional comum e a sua elaboraçáo para, em seguida, ser controlada por avaliação padronizada, censitária, administrada de forma independente ou por organizaçóes do Terceiro Setor ou em articulaçáo com elas. E, ao contrário do que se afirmou na mencionada Audiência Pública, a proposta de BNCC, tal como está construída, propóe definir principalmente como o professor deve ensinar, reduzindo seu protagonismo e autonomia em sala de aula, favorecendo, assim, a utilização de sistemas de ensino pré-fabricados, como aconteceu em São Paulo, com o programa "São Paulo faz escola".

As políticas de responsabilização e de bonificação de professores fazem parte desse pacote de reformas que vem sendo articulado ilegitimamente no MEC, cuja "eficiência" pedagógica deve ser garantida por meio da presença e da internalização de práticas da iniciativa privada na administração educacional. E, por trás disso tudo, está o mercado, a privatização da educação, a criação de uma base mercadológica para a atuaçáo de consultorias, empresas de avaliação e de formação docente e produtoras de material didático e midiático em escala nacional.

Nesse contexto, não podem ser esquecidos os reiterados objetivos de mudanças na formação dos professores da educação básica por meio de reformas dos cursos de Pedagogia das universidades públicas, os quais, como insistem os defensores de tais políticas, devem substituir a formação "excessivamente teórica e política" que realizam, por uma educação mais técnica, ou seja, mais pragmática, mais ajustada aos objetivos da avaliação sistêmica tendo como critério de aferição da qualidade da educação $(\mathrm{COHN}, 1980)$.

$\mathrm{Na}$ nova versão da BNCC, tal como no documento "A travessia social", divulgado pelo Partido do Movimento Democrático Brasileiro (PMDB) às vésperas da votação do impedimento da Presidenta da República no Senado, e no Programa de Aécio Neves para a Educação nas eleiçóes presidenciais de 2014, pro- 
põe-se a adequação da Base à simplificação e à flexibilização do currículo do Ensino Médio, à sua diversificação "segundo o interesse do aluno", a uma vinculação mais estreita ao mercado de trabalho, conforme os propósitos da reforma planejada. Se esse caminho for seguido, ao contrário das orientaçóes das atuais Diretrizes Curriculares Nacionais do Ensino Médio, voltadas ao amplo investimento no Ensino Médio integrado e à constituição de uma escola comum a todos os brasileiros, teremos o reforço da escola dual e reprodutora das desigualdades sociais.

Ao mesmo tempo, deputados fundamentalistas e conservadores apoiados em movimentos como o Unidos pela educação, Escola sem partido ou Escola livre, têm promovido significativa investida ideológica contra os avanços pedagógicos conquistados na formulação da Base. Acusando o "viés marxista da BNCC", propóem nela incluir, ironicamente em nome da liberdade de pensamento, um modelo educacional que proíbe o tratamento, nas escolas, de temáticas relativas à "ideologia" de gênero (relaçôes sociais de gênero), à sexualidade, à "política" (à análise sócio-histórica e à reflexão crítica), além de pretender tolher as manifestações do movimento estudantil. Um dos principais apoiadores desses movimentos é o deputado federal Rogério Marinho que, além de ter apresentado, em 2015, um projeto de lei para "tipificar o crime de assédio ideológico", apresentou recentemente outro projeto de lei favorável à aprovação da Base pelo Congresso Nacional, cuja composiçâo é, no mínimo, preocupante, do ponto de vista social, uma vez que implica sua retirada do âmbito do Conselho Nacional de Educação (CNE) e do MEC.

Como temos nos manifestado na série de Seminários de Educação Brasileira (SEB), promovidos pelo CEDES e em editoriais da revista Educação e Sociedade, tais políticas não são exatamente novas e nem marcam ruptura em relação ao governo anterior da presidenta Dilma. Elas significam a continuidade, nos governos petistas, do viés privatizante herdado do governo Fernando Henrique Cardoso, derivado da nova configuração imposta ao Estado brasileiro. Essa nova configuração promove mudanças quanto à natureza da dimensão pública do Estado, as quais, como enfatiza Cohn (1980), instalaram em seu interior a racionalidade econômica do setor privado, substituindo critérios republicanos de gestão social por critérios privatistas, pautados pela racionalidade do custo/ efetividade, que desconhece a dimensão dos direitos sociais e, como consequência, privilegia a interlocução com os atores do campo empresarial.

No entanto, essa nova gestão pública educacional e sua ofensiva contra a esfera pública, hegemônica nos governos tucano e petistas, não esteve isenta de tensóes, disputas e contradiçóes nos períodos Lula e Dilma. Muitas delas se encontram expressas no texto de lei aprovado pelo Congresso Nacional e sancionado pela Presidente: o Plano Nacional de Educação (PNE). Se os reformadores empresariais e seus prepostos nunca deixaram de atuar no âmbito governamental, impedindo reformas estruturantes e promovendo suas reformas privatistas, também é verdade que sofreram no último período, dentro e fora do aparato estatal, o enfrentamen- 
to permanente por parte de projetos educacionais em defesa da escola pública de qualidade, construídos na luta resistente de movimentos sociais populares e das organizaçóes de educadores democráticos contra as políticas neoliberais de educação. Muitas dessas lutas alcançaram conquistas institucionais, como a ampliação do financiamento via Fundo de Manutenção e Desenvolvimento da Educação Básica e de Valorização dos Profissionais da Educação (FUNDEB), o Piso do Magistério, as Conferências e os Fóruns de Educação, o PNE 2014-2024, os Indicadores de Qualidade na Educação, as políticas de cotas sociais e raciais combinadas à expansão do acesso às universidades e instituições públicas de Ensino Superior, a elevação significativa dos investimentos federais em educação e outras mais.

Ao mesmo tempo, o avanço dos setores privatistas, com suas estratégias de privatização da dinâmica escolar, também se materializou na elaboração do PNE e na desconstrução da importância da Conferência Nacional de Educação mediante a valorização dos decisores privados, tais como institutos e fundaçóes vinculadas a bancos e empresas que influenciam diretamente e "por cima" a política educacional enquanto espaço coletivo de definição da política educacional e nas dificuldades de atuação do FNE.

Tais fatores se expressam claramente na paulatina e constante mudança dos parceiros do MEC na elaboração e operacionalizaçáo das políticas, que agora já não são os professores e pesquisadores das universidades públicas ou as suas entidades representativas, sendo seu lugar agora ocupado por representantes de entidades e fundaçóes privadas vinculadas ao setor empresarial lucrativo e aos grandes bancos. Essa mudança, já perceptível nas gestóes de Lula e Dilma, chega ao seu ápice radical nos primeiros dias do governo interino Temer. Ocorre que, diferentemente daqueles, nesse não há mais contradição ou resistência interna, passando o governo a operar como simples correia de transmissão da agenda proposta pelos reformadores empresariais da educação brasileira.

Ao mesmo tempo, a intensa rotatividade dos técnicos do MEC e o corpo exíguo de funcionários de carreira permitem ao governo interino rapidamente desmontar estruturas institucionais e políticas, já que não há uma burocracia republicana detentora da memória e da identidade do projeto educacional de Estado. Essa foi outra debilidade dos governos petistas, ou seja, a caraterização de políticas públicas em açóes que se mantiveram com caráter de programa, não se configurando como políticas de Estado, capazes de resistir a crises como a que vivemos no presente momento. Pode-se mesmo afirmar que, ao se efetivarem como medidas descontínuas e desarticuladas entre si, não se constituíram nem mesmo como políticas de governo.

Os retrocessos recorrentes no campo educacional, centrados na disputa público versus privado, só podem ser devidamente apreendidos no processo histórico real, ou seja, no movimento mais amplo e contraditório de implementação da política econômica no âmbito das relaçóes entre os governos Lula e Dilma (o "lulismo") e a coalizaçáo produtivista e rentista — como afirma André Singer (2015) ou, como 
prefere Boito Jr. (2012), a grande burguesia interna aliada ao movimento sindical e popular e a grande burguesia integrada e subordinada ao capital estrangeiro.

Tal reflexão, que foi tema de dois números recentes desta revista, não cabe ao escopo deste editorial. Só importa sinalizar aqui que a descaracterização da identidade do projeto educacional do Partido dos Trabalhadores (PT), na prática recorrente do governo Dilma de fazer do MEC "moeda de troca" na negociação política partidária, acabou por enfraquecer os representantes remanescentes da defesa da escola pública, laica, gratuita, democrática e de gestão pública, e por restituir a hegemonia aos reformadores empresariais e setores políticos conservadores, possibilitando o recrudescimento das estratégias privatistas e facilitando sua realização pelo interino e ilegítimo governo de Temer.

Editores da Revista Educação \& Sociedade

\section{Referências}

1. FAGNANI, Eduardo. Mudança na previdência prejudica trabalhadores para favorecer capital. Carta Maior, São Paulo, 2 jun. 2016. Disponível em: <http://cartamaior.com.br/?/ Editoria/Economia/Mudanca-na-Previdencia-prejudica-trabalhadores-para-favorecercapital/7/36221>. Acesso em: 04 jun. 2016

2. FARIA, Luciano Mendes de. A educação em tempos sombrios: perspectivas para a educação no governo Provisório de Temer. Blogdopensar, 26/05/2016. Disponível em: <https:// blogdopensar.wordpress.com/2016/05/26/a-educacao- em-tempos- sombrios-perspectivaspara- a-educacao- no-governo- provisorio-de- temer/>. Acesso em: 04 jun. 2016

3. FREITAS, Luiz Carlos de Freitas. Base nacional (mercadológica) comum. Blog do Freitas. 20/07/2015. Disponível em: <https://avaliacaoeducacional.com/author/freitaslc/>. Acesso em: 04 jun. 2016.

4. COHN, Amélia. O modelo de proteção social no Brasil: qual o espaço da juventude? In: NOVAES, Regina; VANNUCHI, Paulo (Org.). Juventude e sociedade: trabalho, educação, cultura e participação. São Paulo: Ed. Perseu Abramo, 1980. p.160-179.

5. SINGER, André. Cutucando onças com varas curtas. Novos Estudos, São Paulo, n. 102, p. 43-71, julho 2015.

6. BOITO Jr., Armando. Governos Lula: a nova burguesia nacional no poder. In: BOITO Jr., Armando; GALVÃO, Andreia (Org.). Politica e classes sociais no Brasil dos anos 2000. São Paulo: Alameda, 2012. 